\title{
Rapid response in the COVID-19 pandemic: a Delphi study from the European Pediatric Dialysis Working Group
}

\author{
Fabian Eibensteiner ${ }^{1}$ (D) Valentin Ritschl ${ }^{2} \cdot$ Gema Ariceta $^{3} \cdot$ Augustina Jankauskiene $^{4} \cdot$ Günter Klaus $^{5}$. \\ Fabio Paglialonga ${ }^{6}$. Alberto Edefonti ${ }^{6}$. Bruno Ranchin ${ }^{7}$. Claus Peter Schmitt ${ }^{8}$ - Rukshana Shroff ${ }^{9}$. \\ Constantinos J. Stefanidis ${ }^{10}$. Johan Vande Walle ${ }^{11}$. Enrico Verrina ${ }^{12}$ - Karel Vondrak ${ }^{13}$. Aleksandra Zurowska ${ }^{14}$. \\ Tanja Stamm ${ }^{2}$. Christoph Aufricht ${ }^{1}$ (D) On behalf of the European Pediatric Dialysis Working Group
}

Received: 14 April 2020 / Revised: 16 April 2020 / Accepted: 22 April 2020 / Published online: 17 May 2020

(C) The Author(s) 2020

\begin{abstract}
Background COVID-19 was declared a global health emergency. Since children are less than $1 \%$ of reported cases, there is limited information to develop evidence-based practice recommendations. The objective of this study was to rapidly gather expert knowledge and experience to guide the care of children with chronic kidney disease during the COVID-19 pandemic. Methods A four-round multi-center Delphi exercise was conducted among 13 centers in 11 European countries of the European Pediatric Dialysis Working Group (EPDWG) between March, 16th and 20th 2020. Results were analyzed using a mixed methods qualitative approach and descriptive statistics.

Results Thirteen COVID-19 specific topics of particular need for guidance were identified. Main themes encompassed testing strategies and results $(n=4)$, changes in use of current therapeutics $(n=3)$, preventive measurements of transmission and management of COVID-19 $(n=3)$, and changes in standard clinical care $(n=3)$. Patterns of center-specific responses varied according to regulations and to availability of guidelines.

Conclusions As limited quantitative evidence is available in real time during the rapid spread of the COVID-19 pandemic, qualitative expert knowledge and experience represent the best evidence available. This Delphi exercise demonstrates that use of mixed methodologies embedded in an established network of experts allowed prompt analysis of pediatric nephrologists' response to COVID-19 during this fast-emerging public health crisis. Such rapid sharing of knowledge and local practices is
\end{abstract}

Electronic supplementary material The online version of this article (https://doi.org/10.1007/s00467-020-04584-6) contains supplementary material, which is available to authorized users.

Christoph Aufricht

christoph.aufricht@meduniwien.ac.at

1 Division of Pediatric Nephrology and Gastroenterology, Comprehensive Center for Pediatrics, Medical University of Vienna, Waehringer Guertel 18-20, 1090 Vienna, Austria

2 Section for Outcomes Research, Center for Medical Statistics, Informatics, and Intelligent Systems, Medical University of Vienna, Vienna, Austria

3 Department of Pediatric Nephrology, University Hospital Vall d' Hebron, Barcelona, Spain

4 Pediatric Center, Institute of Clinical Medicine, Vilnius University, Vilnius, Lithuania

5 Department of Pediatric Nephrology, KfH Children's Kidney Center, Marburg, Germany

6 Pediatric Nephrology, Dialysis and Transplant Unit, Fondazione IRCCS Ca' Granda Ospedale Maggiore Policlinico, Milan, Italy
7 Department of Pediatric Nephrology, Hôpital Femme Mère Enfant, Hospices Civils de Lyon, Lyon, France

8 Pediatric Nephrology, Center for Child and Adolescent Medicine, Heidelberg, Germany

9 Renal Unit, UCL Great Ormond Street Hospital for Children NHS Foundation Trust, and Institute of Child Health, London, UK

10 Department of Pediatric Nephrology, Mitera Children's Hospital, Athens, Greece

11 Department of Pediatric Nephrology, Utoped, Universitair Ziekenhuis Gent, Ghent, Belgium

12 Dialysis Unit, Department of Pediatrics, IRCCS Giannina Gaslini, Genoa, Italy

13 Department of Pediatric Nephrology, University Hospital Motol, Prague, Czech Republic

14 Department of Pediatric Nephrology, Medical University of Gdansk, Gdansk, Poland 
essential to timely and optimal guidance for medical management of specific patient groups in multi-country health care systems such as those of Europe and the US.

Keywords COVID-19 $\cdot$ Pandemic $\cdot$ Delphi $\cdot$ Dialysis $\cdot$ Transplantation

$\begin{array}{ll}\begin{array}{l}\text { Abbreviations } \\ \text { SARS-CoV-2 }\end{array} & \begin{array}{l}\text { Severe-acute-respiratory-syndrome- } \\ \text { coronavirus-2 }\end{array} \\ \text { COVID-19 } & \begin{array}{l}\text { SARS-CoV-2-related-disease } \\ \text { United States (of America) }\end{array} \\ \text { EPDWG } & \text { European Pediatric Dialysis Working Group } \\ \text { HCP } & \text { Health care personnel } \\ \text { aHUS } & \text { atypical hemolytic uremic syndrome } \\ \text { LRD } & \text { living-related donor } \\ \text { DD } & \text { deceased donor } \\ \text { ECDC } & \text { European Centre for Disease } \\ & \text { Prevention and Control } \\ \text { ACE-I } & \text { Angiotensin-converting-enzyme inhibitors } \\ \text { ARB } & \text { Angiotensin II-receptor-blockers } \\ \text { ESC } & \text { European Society of Cardiology } \\ \text { AHA } & \text { American Heart Association } \\ \text { KDIGO } & \text { Kidney Disease: } \\ & \text { Improving Global Outcomes } \\ \text { HD } & \text { hemodialysis } \\ \text { ICU } & \text { intensive-care units } \\ \text { KTx } & \text { kidney transplantation }\end{array}$

\section{Introduction}

In December 2019, an outbreak of pneumonia of unknown etiology emerged in Wuhan, Hubei province, China. [1-3] The rapid worldwide spread of severeacute-respiratory-syndrome-coronavirus-2 (SARS-CoV2)-related disease (COVID-19) has led to its designation as a global health emergency. [2] By early March 2020, more than 100,000 infections and more than 4000 deaths worldwide were attributable to COVID-19. [4, 5] Most available information on COVID-19 currently stems from the Chinese experience, ultimately characterized by aggressive and uniform public health responses. [6, 7] In contrast, the federalized European states have not introduced uniform countermeasures, which may render their responses more comparable to the US than to the more centralized Chinese public health response. [6, 7]

As fewer than $1 \%$ of reported COVID-19 cases have been children, information about COVID-19 in the pediatric population is sparse. [5, 8-11] The majority of available information concerns the major risk populations, including adults with significant comorbidities and the elderly. [12-21] Consequently, there is an urgent need for information to guide the management of other patient populations. Development of such guidance is especially challenging in highly specialized fields with small target populations, such as pediatric nephrologists caring for children with kidney transplants, receiving dialysis, or being treated with immunosuppressive therapy for kidney disease. There is significant concern that such patients are more likely to develop severe disease due to SARS-CoV-2 infection; yet, they may have an increased risk of exposure due to the need to have ongoing clinical care, including dialysis and laboratory monitoring. The current pandemic provides a challenge to the international community to develop new approaches for rapid analysis and dissemination of information to guide the management of patients with unique healthcare needs.

We hypothesized that application of a mixed method qualitative approach among established international networks of expert groups could very rapidly assess relevant knowledge gaps and retrieve current and evolving evidence of clinical response patterns. [22, 23] To rapidly gather this expert knowledge for the care of children with kidney disease, dialysis, and kidney transplantation during the emerging COVID19 pandemic in Europe, a Delphi exercise was conducted among the European Pediatric Dialysis Working Group (EPDWG).

\section{Methods}

We conducted a four-round Delphi exercise among the Pediatric Nephrology experts from the European Pediatric Dialysis Working Group (EPDWG) using an email survey. The Delphi process provides structured communication, iteration with controlled feedback, and informed input, [24-26] thereby facilitating rapid synthesis of expert knowledge. The emerging COVID-19 pandemic is creating all over Europe a quickly changing and ever more challenging setting in which to provide pediatric nephrology care. This Delphi exercise was conducted within the 5 days from March, 16th, to March 20th, 2020, during the first week of statutory public curfews imposed by local governments across Europe in response to emerging hotspots of SARS-CoV-2.

\section{Participants}

All active EPDWG members representing 16 centers from 13 European countries were asked to participate. At the time of initiation of this Delphi exercise, COVID-19 cases in varying 
numbers had been reported by local authorities in all EPDWG countries.

\section{Data collection and qualitative analysis}

A Delphi exercise uses a series of questionnaires to collect data from multiple panelists. In contrast to other datagathering techniques, Delphi studies use feedback processes (iterations), to develop a consensus concerning a specific topic. This allows participants to reassess their initial judgments at a later time based on information provided earlier. [24] The first Delphi round started with an open email invitation to all EPDWG members to share their current knowledge, experience, information, and guidance for COVID-19 prevention, diagnostics, and management in their target population. Replies were gathered for $24 \mathrm{~h}$. Information provided by the EPDWG members was analyzed using a modified form of meaning condensation analysis. [27, 28] Email replies were first read through to gain an overview of the collected data, after which themes were extracted and clustered according to common meanings. Clustered themes and corresponding quotations for each center were synthesized in a summary of finding table sent to all participants. Thus, participants could see the findings for each theme and center, including their own. The goal of the second Delphi round was to edit the wording, propose amendments, and check correctness of the summaries extracted from the experts' statements. A summary of findings containing the final version of clustered themes and participants' quotations for each center was created. In the third Delphi round, participants were asked to complete information on existing themes they had not addressed previously. Replies from rounds 2 and 3 were collected within $48 \mathrm{~h}$. After the third Delphi round, no new information emerged and data saturation was achieved. Modified meaning condensation analysis $[27,28]$ was further utilized to formulate thematic questions and accompanying answer statements to systematically categorize the whole range of the specific, gathered knowledge. A set of clustered thematic questions and answer statements was created (Table 1). For the fourth Delphi round, this thematic question and answer statement set was circulated, and experts were asked to rate each statement with "total agreement" or "no agreement" in accordance with their local practice. We did not aim at consensus due to the descriptive character of our Delphi exercise, but rather aimed for rapid sharing of knowledge and practices to allow improved guidance of local management.

Descriptive statistics and appropriate graphs were utilized to analyze frequencies and differences in local preparation and practice of pediatric nephrologists for emerging COVID-19. The draft of the manuscript was sent to all participants for their comments, which were addressed in the revised manuscript. The manuscript was submitted after final approval by the EPDWG.

\section{Results}

\section{Participants and response rates}

The invitation to participate was sent out via email to 16 centers from 13 European countries, all active members of the EPDWG. Thirteen centers (81\%) from 11 European countries of the EPDWG (85\%) participated in this Delphi exercise. The participating centers were from Austria, Belgium, Czech Republic, France, Germany, Greece, Italy, Lithuania, Poland, Spain, and the United Kingdom. Each participant completed all four rounds of the Delphi process.

\section{Themes}

During the first round of the Delphi exercise, 13 clustered themes were identified. All themes were included in the second and third rounds of the Delphi exercise. No new themes emerged after the second round, and data saturation was achieved. Among the 13 identified themes, two included testing for COVID-19, two included confirmed COVID-19 cases, three included changes in current therapies, three included preventive and preparatory measures of transmission and management of COVID-19, and three included changes in routine clinical care due to COVID-19.

\section{Statements of current practice}

For the final Delphi round, 13 thematic questions and a varying number of accompanying answer statements were formulated from the gathered data by use of modified meaning condensation analysis. $[27,28]$ Due to data saturation and clarity of statements from the first three Delphi rounds, only six thematic questions and their corresponding answer statements were included in the fourth round. Qualitative and quantitative results are, respectively, displayed in Table 1, Online Resource 1, and in Figs. 1, 2, and 3.

\section{Testing for COVID-19 at the centers of the EPDWG}

Testing asymptomatic patients with increased risk (immunocompromised or dialysis patients) and epidemiologic risk was reported by $46 \%$ (6/13). Testing of patients with other or no chronic disease and epidemiologic risk was reported in $28 \%$ $(5 / 13)$ and $23 \%$ (3/13), respectively. At the time of the study, no asymptomatic patients without epidemiologic risks were routinely tested in the centers of the EPDWG. Regular screening of all asymptomatic health care personnel (HCP) was performed in one center. Screening of asymptomatic HCP upon unprotected contact with suspected or confirmed COVID-19 cases was, respectively, performed in 23\% (3/13) and $62 \%$ (8/13). Testing of symptomatic HCP for COVID-19 regardless of contact, after unprotected contact with suspected, or 
Table 1 Summary of the 13 identified thematic questions, with corresponding frequencies for preformed answer statements among the 13 EPDWG centers

Thematic questions and answer statements

Number $(\%)$

I. Which patients are tested for COVID-19?

Symptomatic patients

$13(100)$

Asymptomatic patients with kidney transplantation and epidemiologic risk

Asymptomatic patients with dialysis and epidemiologic risk

Asymptomatic patients with immunosuppression and epidemiologic risk

Asymptomatic patients with chronic disease and epidemiologic risk

Other asymptomatic patients with epidemiologic risk

Screening of asymptomatic patients without epidemiologic risk

II. Testing of Health Care Personnel for COVID-19?

Screening of all asymptomatic staff members

Screening of asymptomatic staff members upon unprotected contact with suspected

COVID-19 case

Screening of asymptomatic staff members upon unprotected contact with confirmed COVID-19 case

Screening of symptomatic staff members

Screening of symptomatic staff members with history of unprotected contact with suspected COVID-19 case

$10(77)$

Screening of symptomatic staff members with history of unprotected contact with confirmed COVID-19 case

Sent home for quarantine and home office after possible contact

III. Patients with kidney transplantation and confirmed COVID-19?

IV. Patients with dialysis and confirmed COVID-19?

V. Continuation of immunosuppressive therapy?

VI. Discontinuation of ACE-I or ARB therapy?

$0(0)$

VII. Discontinuation of Eculizumab therapy?

$0(0)$

VIII. Dialysis ward triage system?

Information to parents to call when child has COVID-19 symptoms 10 (77

Screening of patients upon entering the dialysis ward 7 (54)

Screening of patients upon entering the hospital

IX. Measures for prevention of SARS-CoV-2 transmission?

Zero visitors or chaperons (including parents)

Only 1 chaperon allowed

Reduction of patient chaperons

$10(77)$

Structural isolation via curtains, rooms, ...

Laminar flow rooms

Separate transportation of patients to the dialysis center

Separation of physicians and nurses for each patient (with registry)

Spreading in different time slots with different teams to avoid coinfection

Face masks for patients

Face masks for physicians

Face masks and high protective gear (suits, face shields, ...) for physicians

Face masks for nurses

Face masks and high protective gear (suits, face shields, ...) for nurses

$\mathrm{X}$. Preparations/provisions for dialysis of SARS-CoV-2-infected patients?

Isolated rooms within own dialysis unit

Isolated rooms within pediatric hospital (e.g. PICU)

Isolated rooms at adult units

Isolated by separate time slots

Separation of medical staff (“COVID-19 teams", physician and nurses)

XI. Changes of Pediatric Kidney Transplantation Program due to COVID-19? 
Table 1 (continued)

Thematic questions and answer statements

Discontinuation of deceased donor kidney transplantation

XII. Suspension of non-urgent care?

Canceling of routine check ups

Canceling of elective procedures (e.g. elective surgery)

Suspension of routine visits of stable kidney transplant patients

Suspension of non-urgent appointments

XIII. Implementation of remote clinical work?

Telephone calls with patients

Video calls with patients

E-Mails with patients

Telemonitoring of patients

Virtual online clinics for patients

No remote clinical work, but reduction of patients

Other, for example: home office with online tutoring and learning

EPDWG European Pediatric Dialysis Working Group, COVID-19 SARS-CoV-2-related-disease, SARS-CoV-2 severe-acute-respiratory-syndrome-coronavirus-2, ACE-I angiotensin-converting-enzyme inhibitors, $A R B$ angiotensin II-receptor-blockers, $P I C U$ pediatric intensive-care unit

confirmed cases was conducted in 69\% (9/13), 77\% (10/13), and $85 \%$ (11/13), respectively. Home quarantine with home office after possible contact of HCP with COVID-19 cases is performed in $69 \%(9 / 13)$.

\section{Confirmed COVID-19 cases at EPDWG centers}

Among 13 centers from 11 European countries, there have been no confirmed cases of COVID-19 in a pediatric dialysis
Fig. 1 Local COVID-19 testing practices at the centers of the EPDWG a Testing of Health Care Personnel for CoviD-19?

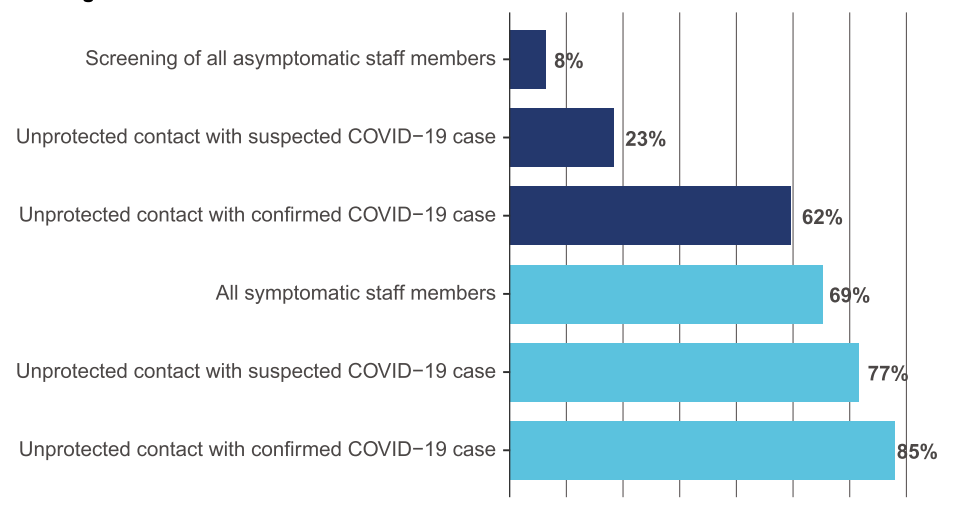

b which patients are tested for COVID-19?

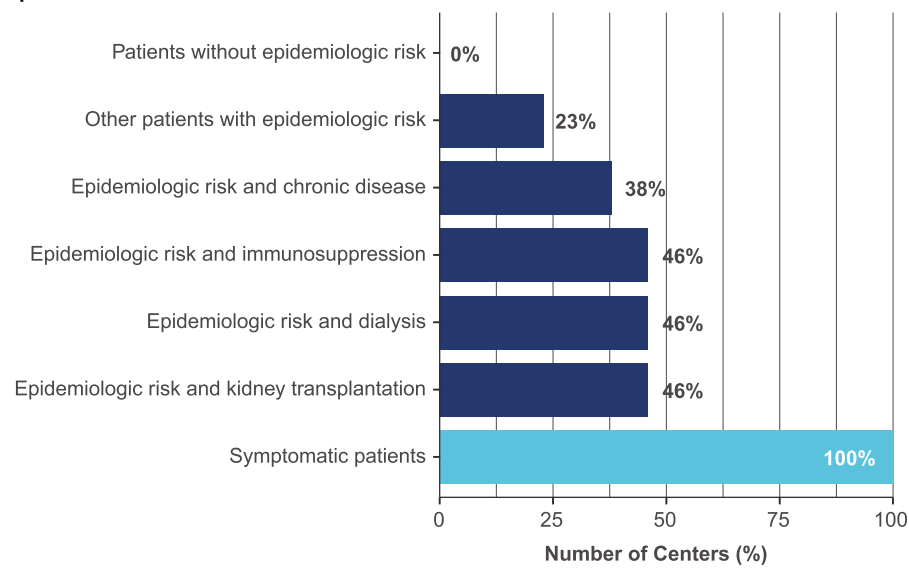

Asymptomatic Health Care Personnel Symptomatic Health Care Personnel 
Fig. 2 Preventive and preparatory measures of transmission and management of confirmed and suspected COVID-19 cases among EPDWG centers
A Dialysis ward triage system?

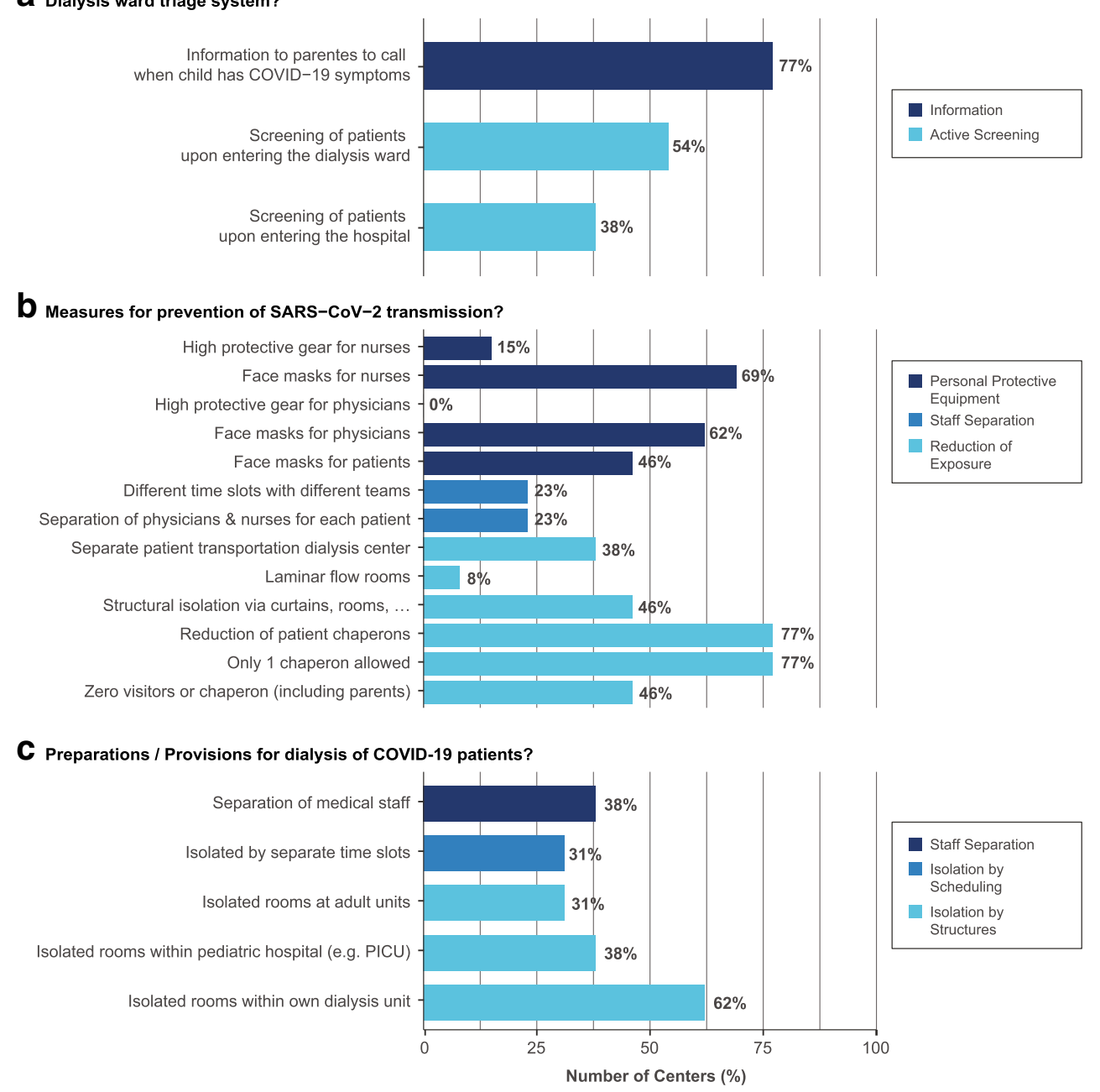

patient and only one in a child with kidney transplant. The latter case occurred in Spain, with the second highest infection and mortality rate for COVID-19 among the 13 centers at the time. The two Italian centers reported no cases of SARS-CoV2-positive children, despite Italy's status as having the highest COVID-19 infection rate.

\section{Changes in current therapies among the EPDWG}

All 13 centers of the EPDWG were in consensus for continuation of immunosuppressive therapy. Statements regarding prophylactic or post-COVID-19 diagnosis discontinuation of ACE-I or ARB therapy in children with renal disease all supported continuation of established therapies. Within the first round of our Delphi exercise, questions arose regarding discontinuation of Eculizumab maintenance therapy for complement-mediated kidney disease, such as atypical hemolytic uremic syndrome (aHUS). During the second and third Delphi rounds, this question was addressed, with consensus toward continuation of therapy.

\section{Preventive and preparatory measures of transmission and management of COVID-19}

Seventy-seven percent (10/13) of EPDWG centers are providing recommendations to parents to contact their pediatric nephrology providers when their child has COVID-19-related symptoms. Thirty-eight percent (5/13) and $54 \%(7 / 13)$ of centers, respectively, perform active screening of patients upon entering the hospital or dialysis ward. Whereas some EPDWG dialysis units can provide isolated rooms for each patient and even laminar flow rooms, others rely on purely organizational measures. The Italian centers of the EPDWG issued guidance that all medical staff and sanitary professionals need to be organized in teams and efficiently protected to avoid coinfection. German centers implemented strategies to be prepared for upcoming delivery shortages, whereas the Czech Republic prescribed during the third Delphi round that face masks were obligatory in public sites. Frequencies for measures of prevention of SARS-CoV-2 transmission are given in Table 1. Isolation of cases in 
Fig. 3 Changes in routine clinical care due to COVID-19 among EPDWG centers a Changes of Transplantation Program?

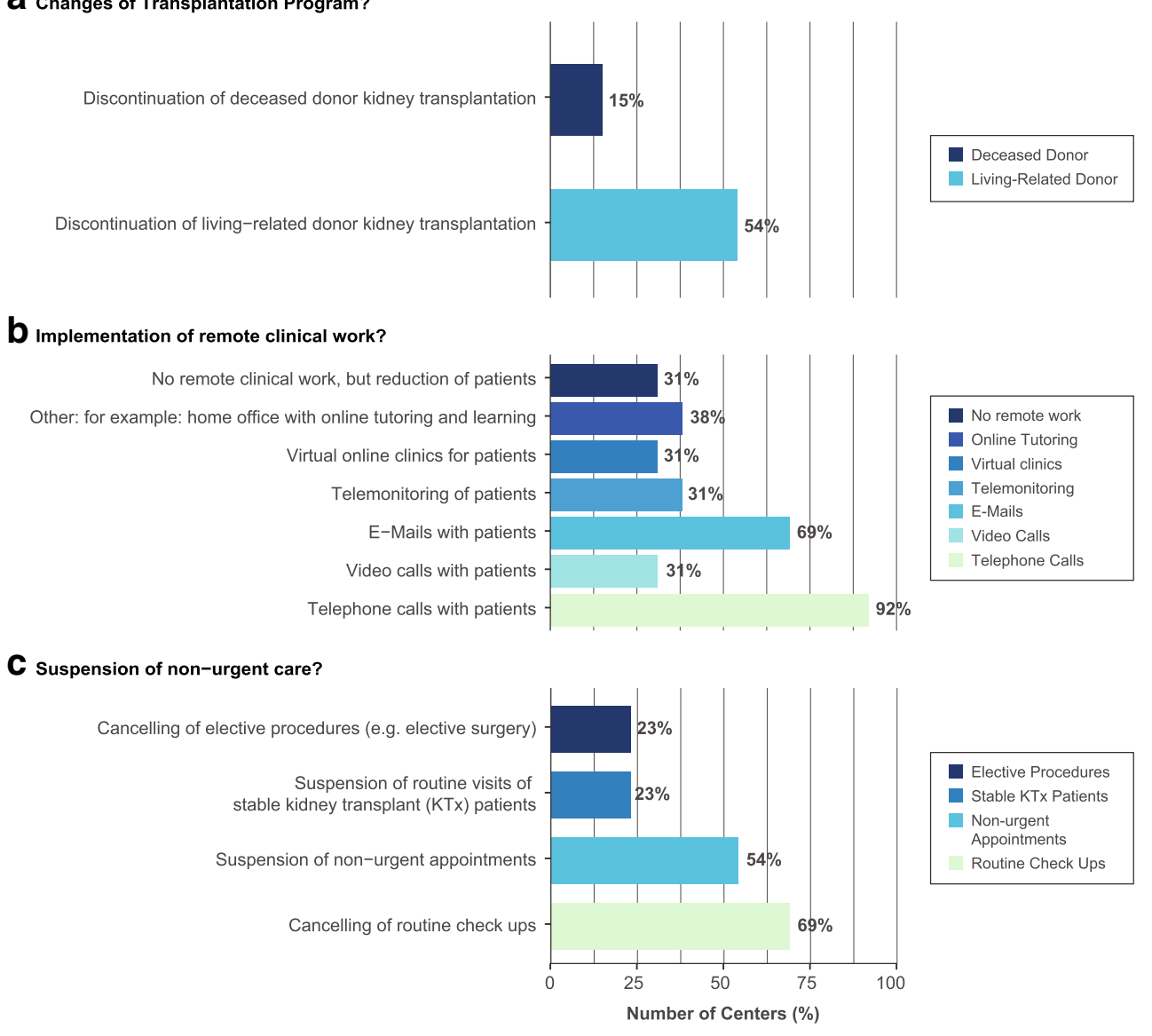

segregated structures within dialysis units, within the pediatric hospitals (e.g., Intensive Care Units) or within adult units was conducted in $62 \%(8 / 13), 38 \%(5 / 13)$, and $31 \%(4 / 13)$ of centers, respectively. Isolation by assignment of cases to different time slots was implemented in $31 \%$ of centers $(4 / 13)$, and separation of medical staff was achieved in $38 \%(5 / 13)$.

\section{Changes in routine clinical care due to COVID-19}

Fifty-four percent (7/13) of EPDWG centers suspended living-related donor (LRD) transplantation. Deceased donor (DD) kidney transplantation was discontinued in $15 \%$ of centers (2/13). At two centers, both LRD and DD transplantation were suspended during the last week of the Delphi exercise. Routine checkups and non-urgent appointments were canceled in $69 \%(9 / 13)$ and $54 \%(7 / 13)$ of centers, respectively. Routine visits for stable pediatric kidney transplant patients were suspended in $23 \%$ of centers $(3 / 13)$. Cancelation of elective procedures and/or surgery was reported in $23 \%$ of centers (3/13). Figure 3 presents specific measures of remote clinical work implemented.

\section{Discussion}

During an acute and rapidly evolving pandemic crisis such as the COVID-19 pandemic, it may appear impossible to generate evidence for recommendation of the management of specific patient groups within short periods of time using standard methodologies. Thus, current recommendations are mostly derived from the reported Chinese experience (and focus on high-incidence groups with high risk). [12-21] This lack of targeted clinical evidence will likely not change within highly specialized fields, such as all pediatric subspecialties. For example, in the recently published pediatric COVID-19 case series (almost exclusively based on Chinese data), no cases of children with kidney transplantation or on dialysis were reported. [5, 8-11]

In this context, expert knowledge, experience, and guidance may provide the best available "evidence". Since COVID-19-specific reports of children with kidney disease, kidney transplantation, or dialysis were unavailable, as was guidance from respective professional societies, we conducted a Delphi exercise among experts in pediatric nephrology, representing 13 centers in 11 European countries (including two Italian centers). The urgency of the situation prompted us to conduct our Delphi exercise with a mixed method 
qualitative approach within 5 days, with four answer rounds of $24 \mathrm{~h}$ each.

Current advice for COVID-19 testing strategies relevant to the EPDWG depends on the stage of the outbreak in different areas, according to the European Centre for Disease Prevention and Control (ECDC). [29] Guidelines for COVID-19 testing of patients and HCP are issued by national authorities, but might be adapted by individual centers depending on local regulations and resources. $[30,31]$ For example, testing of symptomatic patients was uniformly performed in all centers as mandated by health authorities. However, testing of asymptomatic patients and asymptomatic HCP with varying risk factors markedly varied among EPDWG centers, likely reflecting decisions of individual expert teams responsible for clinical care, thus influenced by local expert attitudes and hospital policies. It is important to stress that criteria and strategies for COVID-19 testing are changing rapidly as the geographic spread of COVID-19 expands, as are physician attitudes and hospital policies. In accordance with current literature [5,8-11], our study found no cases of confirmed COVID-19 in children with dialysis. However, we identified the first case of confirmed COVID-19 in a child with kidney transplantation in Spain. This child was doing well at the time of manuscript submission.

Guidance on management of immunosuppressive therapy in adult patients with kidney transplantation and COVID-19 has been recently issued. [32-36] Furthermore, arisen speculations on exacerbation of COVID-19 disease by concurrent treatment with ACE-I or ARB have been addressed by the European Society of Cardiology (ESC) and the American Heart Association (AHA), both strongly recommending continuation of these widely used drugs. [37, 38] Although no such guidance has been published for children, all 13 EPDWG centers were in complete consensus for continuation of these established therapies, while alert to appearance of additional data (for rapid dissemination across the network).

Strategies are emerging to counter acceleration of the COVID-19 pandemic in the face of shortages of resources and personal protective equipment. [31] Concerns about transmission of SARS-CoV-2 to HCP are also emerging more frequently. These might be even more relevant in the pediatric setting, as infected children appear to suffer fewer complications than do their adult HCP. Indeed, up to $20 \%$ of Italian HCP have been infected. [31] KDIGO has recently published guidelines, synthesized from the Chinese and Taiwanese Societies of Nephrology, that recommend separation of HCP and individual patients by location and time, in addition to entrance control, self-monitoring for symptoms, and use of appropriate protective equipment. [34] The EPDWG pattern of responses for prevention and management of SARS-CoV-2 demonstrated varying degrees of implementation of these recommendations across the 13 centers, primarily dependent on available resources, in addition to on local or regional governmental guidelines.

The COVID-19 pandemic led to suspensions of LRD and/ or DD pediatric kidney transplantation programs in most EDPWG centers. These changes in transplantation policies were local decisions within the EPDWG centers and their hospitals, as no health authority regulations were available at the time of the study, and as European and US scientific societies recommended consideration of temporary suspension depending on local circumstances. [32, 39] Implementation of reduction in provision of non-urgent care similarly relied on local practices. Routine checkups and non-urgent appointments were being canceled in most EPDWG centers, whereas routine visits of stable kidney transplant patients and elective were suspended in about $25 \%$ of centers, resulting in significant reduction in direct patient contacts, as recently proposed by the Transplant Society in order to keep transplantation centers operational. [35] Among the EPDWG centers, remote clinical work measures implemented included phone- and video calls, online clinics, and telemonitoring for peritoneal dialysis patients.

Taken together, pediatric nephrology provider response patterns to the challenge of the COVID-19 pandemic have been diverse, as expectable from a multi-country European network in a federalized governmental environment. Responses concerning changes in current treatment were in consensus with recommendations from scientific bodies. However, state-of-the-art tends to be conservative, suggesting change to the status quo only upon presentation of clear evidence of the need for change. Some responses, such as those concerning testing strategies, prevention, and changes in routine care during the COVID-19 pandemic, varied widely among the EPDWG centers, reflecting in part rapid dynamic changes in the responses of national or local health authorities to escalation of the pandemic. Local hospital policies, physicians' attitudes, and available resources also significantly influenced the diverse patterns of responses among EPDWG centers. Future studies, performing detailed longitudinal assessments of these interdependent variables will be needed to obtain a deeper understanding of determinants of individual response patterns. Such studies should be able to compare the efficacy of any country-specific responses to the COVID-19 pandemic.

The strengths of this Delphi exercise lie in the rapid response and communication of 13 expert centers across Europe, with consecutive qualitative data analysis in a thematic field for which no evidence and no guidance from international societies currently exist. The concise description of multi-country European response patterns may allow experts in other countries affected by this pandemic to base their own responses on an improved level of evidence for recommendations unavailable for the time being through standard 
methodologies. The COVID-19 pandemic is expanding in the United States with a lag of about 2 weeks compared to continental Europe. [4] This lag may provide crucial opportunities for US experts to learn from the European areas enduring a more advanced state of the pandemic.

Limitations of this study are inherent in the rapidly evolving pandemic and corresponding dynamics of changing regulations - thus the specific information on response patterns in this study is valid through the date of manuscript submission, and recommendations may change quickly thereafter. However, the consensus identification of specific COVID-19 topics of greatest relevance to a multi-country European expert group working in the midst of the pandemic should be generalizable and may facilitate development of relevant local guidance from other national expert groups or health authorities, supporting individual pediatric nephrology experts in their clinical decision making in a time of extreme uncertainty.

\section{Conclusion}

In conclusion, this Delphi exercise exemplifies international cooperation and communication of experts during a rapidly emerging pandemic crisis. The use of a mixed method qualitative approach allowed retrieval of evidence on international clinical response patterns within an extremely short time. In times at which quantitative data and corresponding evidence under given circumstances is scarce, qualitative expert knowledge, experience, and guidance may be the best evidence available. These principles will apply to every situation in which quantitative evidence is lacking in the setting of an emerging international pandemic threat.

Authors' contributions Dr. F. Eibensteiner and Prof. Dr. C. Aufricht developed concept and design, had full access to all of the data in the study and take responsibility for the integrity and accuracy of the data and subsequent analysis. They drafted the initial manuscript, conducted analysis and interpretation of data and reviewed and revised the manuscript. Data collection as well as critical revision of the manuscript for important intellectual content was done by V. Ritschl, Prof. Dr. G. Ariceta, Prof. Dr. A. Jankauskiene, Prof. Dr. G. Klaus, Prof. Dr. F. Paglialonga, Prof. Dr. A. Edefonti, Prof. Dr. B. Ranchin, Prof. Dr. C. P. Schmitt, Prof. Dr. R. Shroff, Prof. Dr. C. J. Stefanidis, Prof. Dr. J. Vande Walle, Prof. Dr. E. Verrina, Prof. Dr. K. Vondrak, Prof. Dr. A. Zurowska, Prof. Dr. T. Stamm, All authors approved the final manuscript as submitted.

Funding Information Open access funding provided by Medical University of Vienna.

Availability of data and material No data or additional material is made available.

\section{Compliance with ethical standards}

Conflict of interest The authors declare that they have no conflict of interest.
Ethics approval Not applicable.

Consent to participate Consent was obtained from all individual participants included in the study.

Consent for publication Consent for publication was given by each author.

Code availability No custom codes were used for this study.

Open Access This article is licensed under a Creative Commons Attribution 4.0 International License, which permits use, sharing, adaptation, distribution and reproduction in any medium or format, as long as you give appropriate credit to the original author(s) and the source, provide a link to the Creative Commons licence, and indicate if changes were made. The images or other third party material in this article are included in the article's Creative Commons licence, unless indicated otherwise in a credit line to the material. If material is not included in the article's Creative Commons licence and your intended use is not permitted by statutory regulation or exceeds the permitted use, you will need to obtain permission directly from the copyright holder. To view a copy of this licence, visit http://creativecommons.org/licenses/by/4.0/.

\section{References}

1. Huang C, Wang Y, Li X, Ren L, Zhao J, Hu Y, Zhang L, Fan G, Xu J, Gu X, Cheng Z, Yu T, Xia J, Wei Y, Wu W, Xie X, Yin W, Li H, Liu M, Xiao Y, Gao H, Guo L, Xie J, Wang G, Jiang R, Gao Z, Jin Q, Wang J, Cao B (2020) Clinical features of patients infected with 2019 novel coronavirus in Wuhan, China. Lancet 395(10223):497506. https://doi.org/10.1016/S0140-6736(20)30183-5

2. Velavan TP, Meyer CG (2020) The COVID-19 epidemic. Tropical Med Int Health 25(3):278-280. https://doi.org/10.1111/tmi.13383

3. Wang C, Horby PW, Hayden FG, Gao GF (2020) A novel coronavirus outbreak of global health concern. Lancet 395(10223):470 473. https://doi.org/10.1016/S0140-6736(20)30185-9

4. European Centre for Disease Prevention and Control (ECDC) COVID-19 Situation Update Worldwide, as of 22 March 2020. https://www.ecdc.europa.eu/en/geographical-distribution-2019ncov-cases. Accessed March 22, 2020)

5. Lu X, Zhang L, Du H, Zhang J, Li YY, Qu J, Zhang W, Wang Y, Bao S, Li Y, Wu C, Liu H, Liu D, Shao J, Peng X, Yang Y, Liu Z, Xiang Y, Zhang F, Silva RM, Pinkerton KE, Shen K, Xiao H, Xu S, Wong GWK, Chinese Pediatric Novel Coronavirus Study T (2020) SARS-CoV-2 infection in children. N Engl J Med. https://doi.org/ 10.1056/NEJMc2005073

6. Chen S, Yang J, Yang W, Wang C, Bärnighausen T (2020) COVID19 control in China during mass population movements at new year. Lancet 395(10226):764-766. https://doi.org/10.1016/s01406736(20)30421-9

7. Feng S, Shen C, Xia N, Song W, Fan M, Cowling BJ (2020) Rational use of face masks in the COVID-19 pandemic. Lancet Respir Med. https://doi.org/10.1016/s2213-2600(20)30134-x

8. Dong Y, Mo X, Hu Y, Qi X, Jiang F, Jiang Z, Tong S (2020) Epidemiological characteristics of 2143 pediatric patients with 2019 coronavirus disease in China. Pediatrics:e20200702. https:// doi.org/10.1542/peds.2020-0702

9. Ji LN, Chao S, Wang YJ, Li XJ, Mu XD, Lin MG, Jiang RM (2020) Clinical features of pediatric patients with COVID-19: a report of two family cluster cases. World J Pediatr. https://doi.org/10.1007/ s12519-020-00356-2 
10. Xia W, Shao J, Guo Y, Peng X, Li Z, Hu D (2020) Clinical and CT features in pediatric patients with COVID-19 infection: different points from adults. Pediatr Pulmonol. https://doi.org/10.1002/ ppul.24718

11. Xu Y, Li X, Zhu B, Liang H, Fang C, Gong Y, Guo Q, Sun X, Zhao D, Shen J, Zhang H, Liu H, Xia H, Tang J, Zhang K, Gong S (2020) Characteristics of pediatric SARS-CoV-2 infection and potential evidence for persistent fecal viral shedding. Nat Med. https://doi. org/10.1038/s41591-020-0817-4

12. He F, Deng Y, Li W (2020) Coronavirus disease 2019 (COVID-19): what we know? J Med Virol. https://doi.org/10.1002/jmv.25766

13. Murthy S, Gomersall CD, Fowler RA (2020) Care for critically ill patients with COVID-19. Jama. https://doi.org/10.1001/jama.2020. 3633

14. Onder G, Rezza G, Brusaferro S (2020) Case-fatality rate and characteristics of patients dying in relation to COVID-19 in Italy. Jama. https://doi.org/10.1001/jama.2020.4683

15. Tian S, Hu N, Lou J, Chen K, Kang X, Xiang Z, Chen H, Wang D, Liu N, Liu D, Chen G, Zhang Y, Li D, Li J, Lian H, Niu S, Zhang L, Zhang J (2020) Characteristics of COVID-19 infection in Beijing. J Inf Secur. https://doi.org/10.1016/j.jinf.2020.02.018

16. Wei M, Yuan J, Liu Y, Fu T, Yu X, Zhang ZJ (2020) Novel coronavirus infection in hospitalized infants under 1 year of age in China. Jama. https://doi.org/10.1001/jama.2020.2131

17. Weiss P, Murdoch DR (2020) Clinical course and mortality risk of severe COVID-19. Lancet. https://doi.org/10.1016/s0140-6736(20) 30633-4

18. Wu C, Chen X, Cai Y, Xia J, Zhou X, Xu S, Huang H, Zhang L, Zhou X, Du C, Zhang Y, Song J, Wang S, Chao Y, Yang Z, Xu J, Zhou X, Chen D, Xiong W, Xu L, Zhou F, Jiang J, Bai C, Zheng J, Song Y (2020) Risk factors associated with acute respiratory distress syndrome and death in patients with coronavirus disease 2019 pneumonia in Wuhan, China. JAMA Intern Med. https://doi.org/10. 1001/jamainternmed.2020.0994

19. Wu Z, McGoogan JM (2020) Characteristics of and important lessons from the Coronavirus disease 2019 (COVID-19) outbreak in China: summary of a report of 72314 cases from the Chinese Center for Disease Control and Prevention. Jama. https://doi.org/10.1001/ jama.2020.2648

20. Zhou F, Yu T, Du R, Fan G, Liu Y, Liu Z, Xiang J, Wang Y, Song B, Gu X, Guan L, Wei Y, Li H, Wu X, Xu J, Tu S, Zhang Y, Chen H, Cao B (2020) Clinical course and risk factors for mortality of adult inpatients with COVID-19 in Wuhan, China: a retrospective cohort study. Lancet. https://doi.org/10.1016/s0140-6736(20)30566-3

21. Zhu N, Zhang D, Wang W, Li X, Yang B, Song J, Zhao X, Huang B, Shi W, Lu R, Niu P, Zhan F, Ma X, Wang D, Xu W, Wu G, Gao GF, Tan W, China Novel Coronavirus I, Research T (2020) A novel coronavirus from patients with pneumonia in China, 2019. N Engl J Med 382(8):727-733. https://doi.org/10.1056/NEJMoa2001017

22. Hoffman JM, Keeling NJ, Forrest CB, Tubbs-Cooley HL, Moore E, Oehler E, Wilson S, Schainker E, Walsh KE (2019) Priorities for pediatric patient safety research. Pediatrics 143(2). https://doi.org/ 10.1542/peds.2018-0496

23. Merandi J, Vannatta K, Davis JT, McClead RE Jr, Brilli R, Bartman $\mathrm{T}$ (2018) Safety II behavior in a pediatric intensive care unit. Pediatrics 141(6). https://doi.org/10.1542/peds.2018-0018

24. Bauernfeind B, Aringer M, Prodinger B, Kirchberger I, Machold K, Smolen J, Stamm T (2009) Identification of relevant concepts of functioning in daily life in people with systemic lupus erythematosus: a patient Delphi exercise. Arthritis Rheum 61(1):21-28. https:// doi.org/10.1002/art.24165

25. Goodman CM (1987) The Delphi technique: a critique. J Adv Nurs 12(6):729-734. https://doi.org/10.1111/j.1365-2648.1987. tb01376.x
26. Linstone HA, Turoff M (1975) The Delphi method: techniques and applications. Addison-Wesley Pub. Co., Advanced Book Program

27. Ritschl V, Lackner A, Bostrom C, Mosor E, Lehner M, Omara M, Ramos R, Studenic P, Smolen JS, Stamm TA (2018) I do not want to suppress the natural process of inflammation: new insights on factors associated with non-adherence in rheumatoid arthritis. Arthritis Res Ther 20(1):234. https://doi.org/10.1186/s13075-0181732-7

28. Stamm TA, Mattsson M, Mihai C, Stocker J, Binder A, Bauernfeind B, Stummvoll G, Gard G, Hesselstrand R, Sandqvist G, Draghicescu O, Gherghe AM, Voicu M, Machold KP, Distler O, Smolen JS, Bostrom C (2011) Concepts of functioning and health important to people with systemic sclerosis: a qualitative study in four European countries. Ann Rheum Dis 70(6):1074-1079. https://doi.org/10.1136/ard.2010.148767

29. European Centre for Disease Prevention and Control (ECDC) Questions and answers on COVID-19. https://www.ecdc.europa. $\mathrm{eu} / \mathrm{en} /$ novel-coronavirus-china/questions-answers. Accessed March 20, 2020)

30. Federal Ministry Repbulic of Austria, Social Affairs, Health Care and Consumer Protection Criteria for testing COVID-19. https:// www.sozialministerium.at/dam/jcr:dc6704c4-49f3-40e4-b0389b5da8aa3067/Erlass BMSGPK.pdf. Accessed March 20, 2020)

31. The L (2020) COVID-19: protecting health-care workers. Lancet 395(10228). https://doi.org/10.1016/s0140-6736(20)30644-9

32. European Renal Association - European Dialysis and Transplant Association (ERA-EDTA) News and Information for the ERAEDTA community and kidney patients. https://www.era-edta.org/ en/covid-19-news-and-information/\#toggle-id-6. Accessed March 20, 2020)

33. Michaels MG, La Hoz RM, Danziger-Isakov L, Blumberg EA, Kumar D, Green M, Pruett TL, Wolfe CR (2020) Coronavirus disease 2019: implications of emerging infections for transplantation. Am J Transplant. https://doi.org/10.1111/ajt.15832

34. Naicker S, Yang C-W, Hwang S-J, Liu B-C, Chen J-H, Jha V (2020) The Novel Coronavirus 2019 epidemic and kidneys. Kidney Int. https://doi.org/10.1016/j.kint.2020.03.001

35. The Transplant Society Guidance on Coronavirus Disease 2019 (COVID-19) for Transplant Clinicians. https://tts.org/tid-about/tidpresidents-message/23-tid/tid-news/657-tid-update-and-guidanceon-2019-novel-coronavirus-2019-ncov-for-transplant-id-clinicians. Accessed March 20, 2020)

36. European Society of Organ Transplantation (ESOT) Statement on COVID-19 Outbreak. https://www.esot.org/news/latest-news/esotstatement-covid-19-outbreak. Accessed March 20, 2020)

37. European Society of Cardiology (ESC) Position Statement of the ESC Council on Hypertension on ACE-Inhibitors and Angiotensin Receptor Blockers. https://www.escardio.org/Councils/Council-onHypertension-(CHT)/News/position-statement-of-the-esc-councilon-hypertension-on-ace-inhibitors-and-ang. Accessed March 20, 2020)

38. HFSA/ACC/AHA (American Heart Association) statement addresses concerns re:using RAAS antagonists in COVID-19. https://professional.heart.org/professional/ScienceNews/UCM 505836 HFSAACCAHA-statement-addresses-concerns-re-usingRAAS-antagonists-in-COVID-19.jsp. Accessed March 20, 2020)

39. American Society of Transplantation (AST) Coronavirus Disease 2019 (COVID-19): Frequently Asked Questions from Transplant Candidates and Recipients. https://www.myast.org/coronavirusdisease-2019-covid-19-frequently-asked-questions-transplantcandidates-and-recipients. Accessed March 20, 2020)

Publisher's note Springer Nature remains neutral with regard to jurisdictional claims in published maps and institutional affiliations. 